\title{
Effects of varying probability of a response-pause \\ requirement on a regular reinforcement baseline ${ }^{1}$
}

W. N. SCHOENFELD, ${ }^{2}$ JOHN FARMER, and CHRISTOPHER VICKERY, Queens College of the City University of New York, Flushing, N.Y. 11367

The bar-press response of two rats was maintained on a reinforcement schedule in which the probability (p) that a response-pause ("not- $R$ ") requirement would follow any given reinforcement $(S R)$ varied between zero (conventional "CRF") and unity (conventional "DRL"). Both the interresponse-time (IRT) and postreinforcement-pause $\left(P S^{R} P\right)$ distributions were affected by this experimental variable. Recoverability of data was generally good at those $p$ values tested but was markedly slow immediately following exposure to $p=1.00$.

Some research (Schoenfeld \& Farmer, in press) has shown that reinforcements applied to behavior other than responding (not-R, or $\mathbb{R}$ ) produce systematic changes in response ( $R$ ) measures. One experiment reported the effects of concurrently reinforcing both responding and not-responding, and another the effects of reinforcing the chain $\mathbb{R} \rightarrow \mathbf{R} \rightarrow \mathbb{R}$. The present study is of the chain $R \rightarrow R$ under varying probabilities that the first link (k) is required for reinforcement. period with no $R$ (in this case, bar-press). The probability, $p$, that the $R$ link of the $\mathbf{R} \rightarrow \mathbf{R}$ chain is required for reinforcement is varied from 0.0 to 1.0 . When $p=0.0$, the conventional CRF schedule obtains, while $p=1.0$ defines the conventional DRL $5-\mathrm{sec}$ schedule.

\section{METHOD}

Two Sprague-Dawley rats maintained at $80 \%$ body weight, with age-growth corrections estimated by Zucker's (1953) formula, served as Ss. After bar-press training, the animals were allowed 256 reinforcements (each reinforcement being $3 \mathrm{sec}$ access to a condensed-milk and water mixture) at $p=0.0$ in each of 10 successive sessions. The sequence of values assigned to $p$ and the length of exposure to each $p$ are given in Table 1.

\section{RESULTS AND DISCUSSION}

The data in Figs. 1 and 2 indicate that the independent variable, probability of the $k$ requirement, acted to control the interresponse time (IRT) and postreinforcement pause (PSRP)
For this study, $k$ is defined as a 5 -sec distributions independently. (IRT distributions include all temporal separations of $\mathrm{Rs}$ in which no $\mathrm{S}^{\mathrm{R}} \mathrm{S}$ occur.) The modal IRTs at about 5 sec developed at much lower probabilities than the 5 -sec modal PSRPs. At the lower probabilities $(p \leqslant 0.75)$, the animals generally responded immediately after reinforcement and either were reinforced immediately or else paused for about $5 \mathrm{sec}$ before responding again. Unreinforced responses, whether occurring shortly after a reinforcement or after a pause close to $5 \mathrm{sec}$ long, were generally followed by a few short IRTs before the next long IRT started. This pattern of responding produced the bunching of IRTs at about $1 \mathrm{sec}$ for both rats and corresponds to

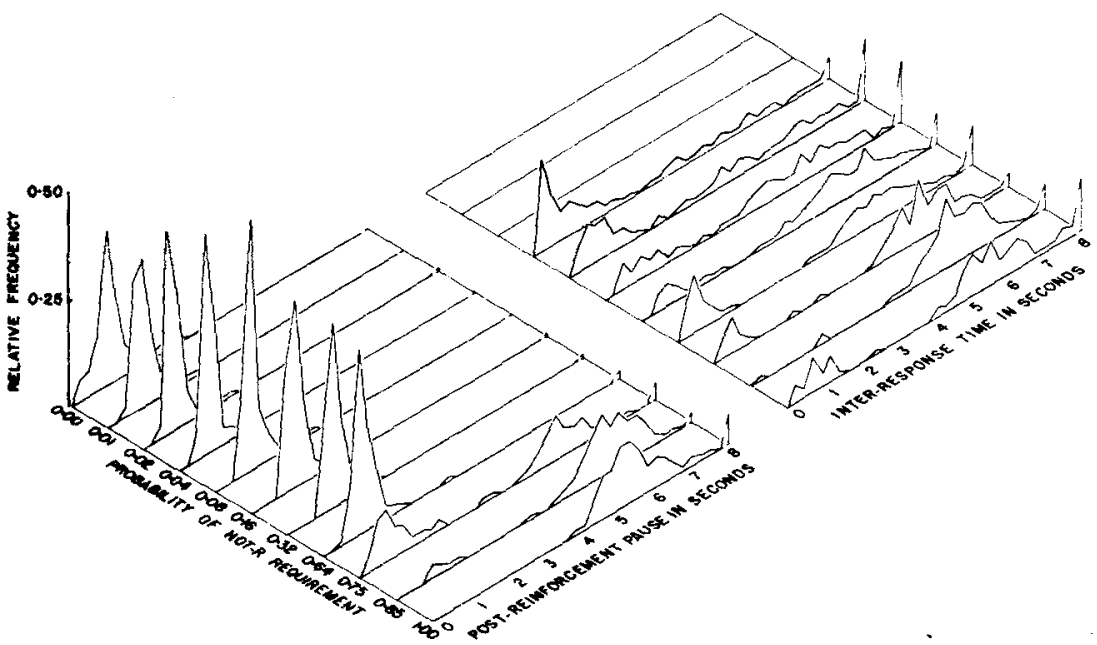

Fig. 1. Postreinforcement pause (PS $\left.R_{P}\right)$ and interresponse-time (IRT) distributions recorded from the last two to five sessions at each probability $(p)$ of the requirement for Rat 1. (IRT distributions include all temporal separations of $R s$ in which no $S^{R_{S}}$ occur.) The sample size for each $\operatorname{PS}^{R} \mathbf{P}$ distribution is 255 . The sample sizes for the IRT distributions are: $p=0.04,169 ; p=0.08,179 ; p=0.16,233 ; p=0.32,273 ; p=0.64$, $384 ; p=0.75,158 ; p=0.85,109 ; p=1.00,195$. Although the abscissa probability axis is arranged ordinally, Table 1 gives the actual sequence of exposures and the length of time (in sessions of 256 reinforcements each) spent at each probability value. No IRT distributions were constructed for $p<0.04$ because the sample size was too small.

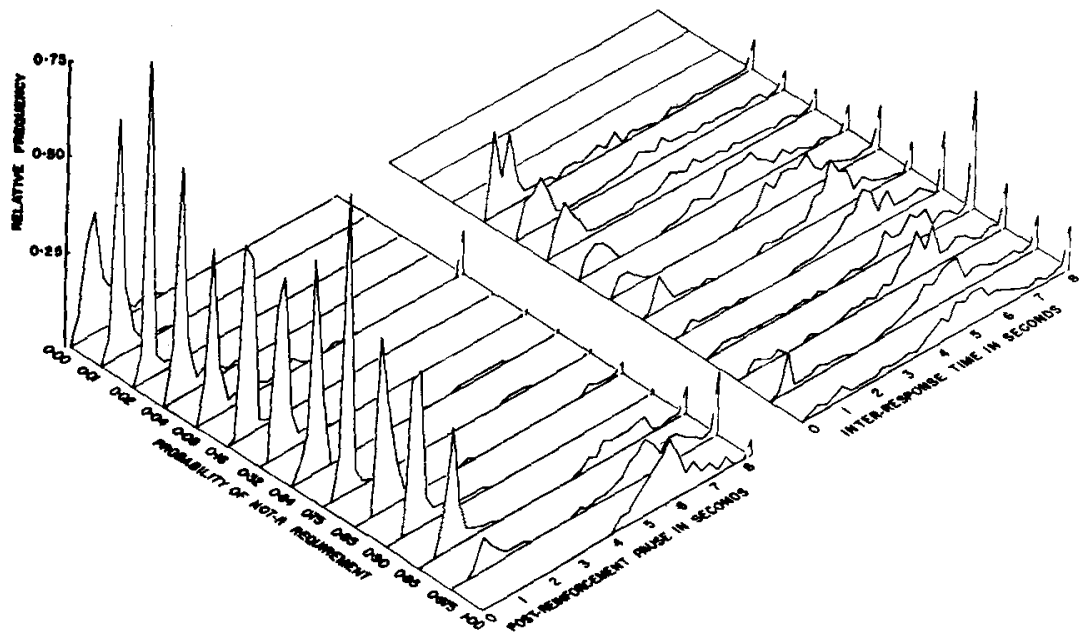

Fig. 2. Same as Fig. 1 for Rat 2. IRT sample sizes are: $P=0.04,174 ; p=0.08,321$; $p=0.16,688 ; p=0.32,203 ; p=0.64,264 ; p=0.75,282 ; p=0.85,298 ; p=0.90,274 ;$ $p=0.95,188 ; p=0.975,180 ; p=1.00,773$. 
Table 1

\begin{tabular}{cccc}
\hline & Rat 1 & & Rat 2 \\
\cline { 1 - 2 } $\begin{array}{c}\text { Number } \\
\text { of } \\
\text { Sessions }\end{array}$ & & p & $\begin{array}{c}\text { Number } \\
\text { of } \\
\text { Sessions }\end{array}$ \\
\hline 0.00 & 10 & 0.00 & 10 \\
0.01 & 5 & 0.01 & 5 \\
0.02 & 7 & 0.02 & 7 \\
0.04 & 7 & 0.04 & 7 \\
0.08 & 11 & 0.08 & 11 \\
0.16 & 13 & 0.16 & 13 \\
0.32 & 10 & 0.32 & 10 \\
0.64 & 10 & 0.64 & 10 \\
1.00 & 10 & 1.00 & 10 \\
0.64 & 51 & 0.64 & 51 \\
0.75 & 10 & 0.75 & 10 \\
0.65 & 15 & 0.85 & 13 \\
1.00 & 12 & 0.90 & 10 \\
0.00 & 33 & 0.95 & 10 \\
0.32 & 10 & 0.975 & 13 \\
& & 1.00 & 14 \\
& & 0.32 & 10 \\
\hline
\end{tabular}

findings reported elsewhere for conventional DRL schedules (Sidman, 1956; Ferraro et al, 1965).

The recovery data presented in Figs. 3 and 4 demonstrate the powerful effect of the sequence in which the animals were exposed to the various probabilities. Once the animals had been exposed to $p=1.00$, return to the original performance at $p=0.64$ was gradual; only after more than 50 sessions had both animals recovered their earlier pattern of responding, and Fig. 3 shows that Rat 1 still made more PSR Ps of about $5 \mathrm{sec}$ than originally. Nonetheless, the form of the distributions was recovered in all cases.

It is evident that the simple stream of behavior $\left(\ldots R \rightarrow S^{R} \rightarrow R \rightarrow S^{R} \ldots\right)$ can be controlled systematically by varying the frequency with which a requirement is introduced into the stream. In the present case, the effect upon the inter-R time (or, IRT) measure was seen at lower probabilities than the effect upon the $\mathrm{SR} \rightarrow \mathrm{R}$ (or, PSRP) time measure. The length of the required $R$ that is introduced into the behavior stream will, of course, be a parameter of the result reported here.
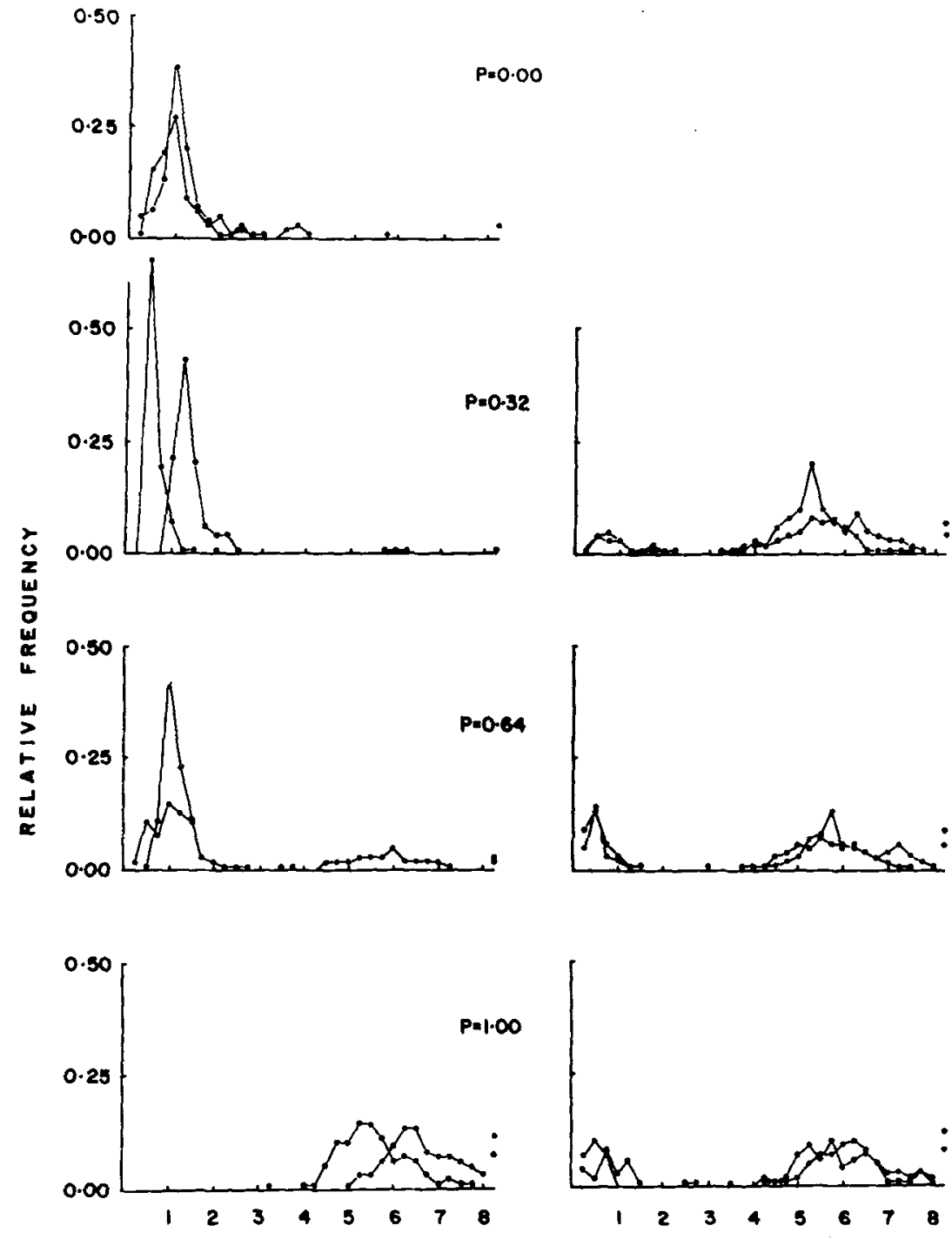

POST-REWFORCEMENT PAUSE W SECONDS

Fig. 3. PSRP and IRT distributions for original (filled circles) and recovery (open circles) exposures to various probabilities of the $\mathbb{A}$ requirement for $R$ at 1 . Sample sizes for the original IRT distributions are given in the legend for $G$ if. 1 and were as follows for the redeterminations: $p=0.32,180 ; p=0.64,161 ; p=1.00,153$. 

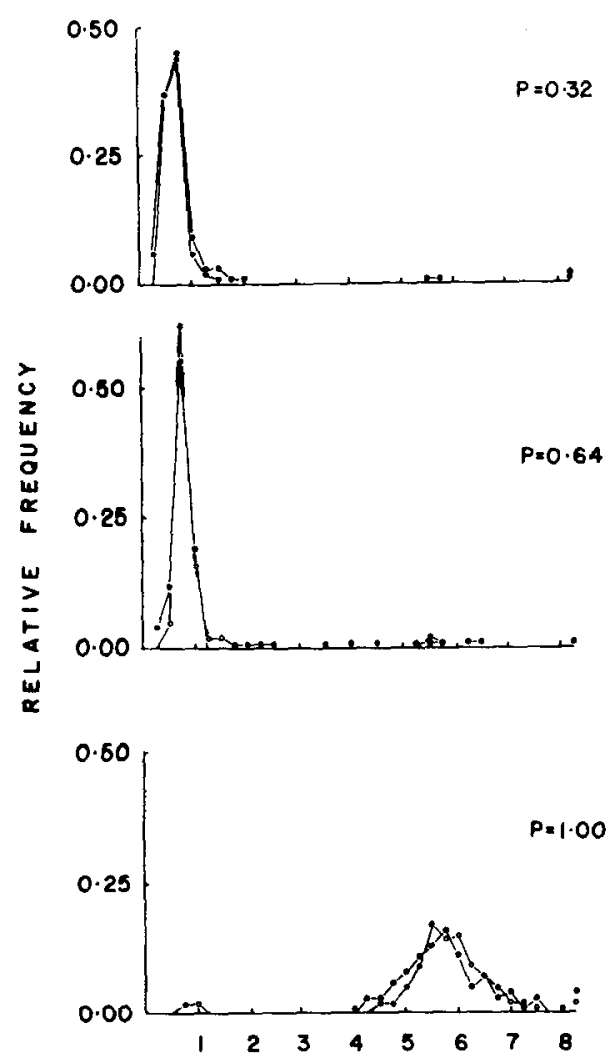

POST-REINFORCEMENT PAUSE IN SECONDS

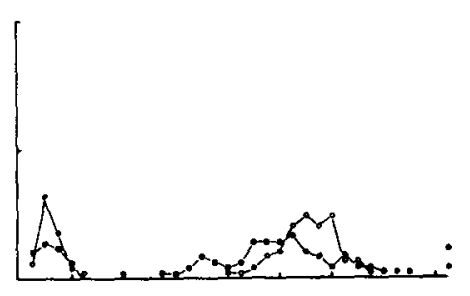

Fig. 4. Same as Fig. 3 for Rat 2. Sample sizes for IRT recovery functions are: $\mathrm{p}=0.32,182 ; \mathrm{p}=0.64,399 ; \mathrm{p}=\mathbf{1 . 0 0}$, 177.

\section{REFERENCES}

FERRARO, D. P., SCHOENFELD, W. N., \& SNAPPER, A. G. Sequential response effects in the white rat during conditioning and extinction on a DRL schedule. Joumal of the Experimental Analysis of Behavior, 1965, 8, 255-260.

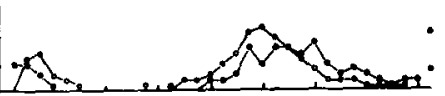

CHOENFELD, W. N., \& FARMER, J. Reinforcement schedules and the "behavior stream." In W. N. Schoenfeld (Ed.), Theories of reinforcement schedules New York: Appleton-Century-Crofts, in press.

SIDMAN, M. Time discrimination and behavioral interaction in a free operant situation. Joumal of Comparative \& Physiological Psychology, $1956,49,469-473$.

ZUCKER, L. Growth criteria. In: Rat quality, a consideration of heredity, diet, and disease. Proceedings of the National Vitamin Foundation Symposium. New York: National Vitamin Foundation, 1953.

$$
\text { NOTES }
$$

1. This investigation was supported by Public Health Research Grants MH 08006 and MH 12964 from the National Institute of Mental Health.

INTER-RESPONSE TME IN SECONDS

2. Also of Cornell University Medical College. 